\title{
Microbial epidemiology and risk factors for relapse in gram-negative bacteria catheter- related bloodstream infection with a pilot prospective study in patients with catheter removal receiving short-duration of antibiotic therapy
}

Bhitta Surapat ${ }^{1}$, Preecha Montakantikul ${ }^{2}$, Kumthorn Malathum ${ }^{3}$, Sasisopin Kiertiburanakul ${ }^{3}$, Pitak Santanirand ${ }^{4}$ and Busba Chindavijak ${ }^{2^{*}}$

\begin{abstract}
Background: Infectious Diseases Society of America (IDSA) guidelines suggest 7-14 days' duration of antibiotic treatment for uncomplicated Gram-negative bacteria (GNB) catheter-related bloodstream infection (CRBSI). The objectives of this study were to review microbial epidemiology, to determine rate and risk factors for relapse, and to compare clinical outcomes in patients receiving long-versus short-duration antibiotic therapy.

Methods: A retrospective phase 1 study was conducted between January 2010 and October 2016 to review microbial epidemiology and to determine the incidence of and risk factors for relapse in patients with GNB CRBSI, according to the IDSA guidelines diagnostic criteria. In phase 2 of the study, patients without risk factors for relapse between November 2016 and October 2017 were prospectively recruited to receive antibiotic therapy for 7 days after catheter removal. Matched patients from the retrospective phase 1 study who had received antibiotic therapy for $\geq 14$ days were selected as a phase 2 control group to compare outcomes.

Results: In phase 1, three most common pathogens identified among 174 cases were Pseudomonas aeruginosa (22.0\%), Klebsiella pneumoniae (16.7\%), and Stenotrophomonas maltophilia (13.4\%). Eighty-nine episodes of infection occurred while patients were receiving antibiotic therapy. Of 140 cases, the relapse rate was 6.4\%. Catheter retention was the only risk factor strongly associated with relapse (odds ratio $=145.32$; $95 \%$ confidence interval 12.66-1667.37, $P<0.001$ ). In phase 2,11 patients with catheter removal were prospectively recruited to receive short-duration therapy. The number of patients with relapse receiving long- or short-duration therapy was 1 (3\%) and $0(0 \%)$, respectively $(P=1.000)$.

(Continued on next page)
\end{abstract}

\footnotetext{
* Correspondence: busba.chi@mahidol.ac.th

${ }^{2}$ Department of Pharmacy, Faculty of Pharmacy, Mahidol University, Bangkok,

Thailand

Full list of author information is available at the end of the article
}

(c) The Author(s). 2020 Open Access This article is licensed under a Creative Commons Attribution 4.0 International License, which permits use, sharing, adaptation, distribution and reproduction in any medium or format, as long as you give appropriate credit to the original author(s) and the source, provide a link to the Creative Commons licence, and indicate if changes were made. The images or other third party material in this article are included in the article's Creative Commons licence, unless indicated otherwise in a credit line to the material. If material is not included in the article's Creative Commons licence and your intended use is not permitted by statutory regulation or exceeds the permitted use, you will need to obtain permission directly from the copyright holder. To view a copy of this licence, visit http://creativecommons.org/licenses/by/4.0/ The Creative Commons Public Domain Dedication waiver (http://creativecommons.org/publicdomain/zero/1.0/) applies to the data made available in this article, unless otherwise stated in a credit line to the data. 
(Continued from previous page)

Conclusions: For the management of patients with uncomplicated GNB CRBSI, empiric broad-spectrum antibiotic therapy with adequate coverage of $P$. aeruginosa should be chosen. Catheter removal should be performed to prevent relapse and shortening the duration of treatment could be considered.

Trial registration: Thai Clinical Trial Registry: TCTR20190914001. Retrospectively registered on 13 September 2019.

Keywords: Duration, Catheter removal, Pseudomonas aeruginosa

\section{Background}

Catheter-related bloodstream infection (CRBSI) is one of the most important healthcare-associated infections. In the past, the most common causative pathogens of CRBSI were Gram-positive bacteria, such as coagulasenegative staphylococci and Staphylococcus aureus [1-3]. However, recent global data have reported that the epidemiology of CRBSI has changed, with a predominance of Gram-negative bacteria (GNB), such as Pseudomonas aeruginosa, Klebsiella spp., or Acinetobacter spp. as the causative pathogen [4-7].

For the treatment of uncomplicated GNB CRBSI, the clinical practice guidelines for the diagnosis and management of intravascular catheter-related infection by the Infectious Diseases Society of America (IDSA) suggests antibiotic therapy of 7-14 days [8]. However, this treatment recommendation came from expert opinions, which is different from recommendations for Grampositive CRBSI that were based on stronger and better quality of evidence [8]. In Thailand, there is no local treatment guidelines and the IDSA guidelines are mainly followed by Thai physicians. Despite the 7-14 day range for treatment suggested in the guidelines [8], most physicians prefer to prolong antibiotic therapy to 10-14 days, even in patients whose catheters have been removed. Understanding the nature of this disease in terms of relapse could help reducing unnecessary antibiotic use. Thus, the objectives of this study were to review microbial epidemiology to determine relapse rates, and to identify patients with low risk for relapse, as potential candidates for short-duration antibiotic therapy.

\section{Methods}

\section{Setting and patients}

The study was conducted in two phases at Ramathibodi hospital, Mahidol University (a 1200-bed university hospital in Bangkok, Thailand). Phase 1 was a retrospective cohort study to review microbial epidemiology and to find the incidence and risk factors for relapse in patients with GNB CRBSI. Phase 2 was a nonrandomized, historically controlled study to compare rates of relapse in GNB CRBSI patients with catheter removal with low risk of relapse who received long- versus short-duration antibiotic treatment.
Phase 1 collected data from hospitalized adult patients aged $\geq 18$ years between January 2010 and October 2016 . These patients had culture proven GNB CRBSI, according to 2009 IDSA diagnostic criteria (patients with bacteremia with differential time to catheter culture positivity versus peripheral hemoculture of $>2 \mathrm{~h}$, or semiquantitative catheter culture of $>15$ colony-forming unit per catheter segment whereby the same organism is recovered from the catheter segment and the peripheral hemoculture) [8]. This included patients with nosocomial infection, which was defined as patients with positive hemoculture obtained $>48 \mathrm{~h}$ after hospital admission or within $48 \mathrm{~h}$ after discharge [9]. Patients who had positive hemoculture obtained within $48 \mathrm{~h}$ of admission were classified as community-acquired infection, except for those who attended hemodialysis clinic or received intravenous chemotherapy within 30 days, or were hospitalized for $>2$ days within 90 days would be classified as healthcare-associated infection [10]. In the clinical analysis, all included patients must have been administered appropriate antibiotic treatment. Appropriate treatment was defined as receiving at least one active agent based on an in vitro susceptibility profile via a systemic route (intravenous or oral) with or without antibiotic lock therapy. Patients with persistent bacteremia, suppurative thrombophlebitis, septic emboli, or other metastatic infectious complications, such as infective endocarditis, septic arthritis, osteomyelitis, spondylodiscitis, and deep-seated abscess were excluded.

Phase 2 recruited hospitalized adult patients aged $\geq 18$ years, between November 2016 and October 2017. These patients had GNB CRBSI, according to the 2009 IDSA definition, and were treated with appropriate antibiotics. Patients were excluded if they (1) had not had their catheters removed; (2) had risk factors for relapse according to the phase 1 study's results; (3) had a prosthetic valve or synthetic endovascular grafts; (4) had neutropenia (absolute neutrophil count $<500 / \mathrm{mm}^{3}$ ), as evaluated on their antibiotic discontinuation day; (5) had persistent bacteremia, suppurative thrombophlebitis, septic emboli, or other metastatic infectious complications, such as infective endocarditis, septic arthritis, osteomyelitis, spondylodiscitis, or deep-seated abscess, as evaluated on their antibiotic discontinuation day; or 
(6) had other indications for receiving antibiotics with the activity against the causative CRBSI pathogen for more than 7 days.

\section{Data collection}

Patients' demographic and clinical data were recorded. Patients were monitored for outcomes (relapse and death) in a follow-up period of 30 days after antibiotic discontinuation. Because some patients might receive an antibiotic that was active against the CRBSI pathogen during the follow-up period for other reasons, the time to next antibiotic use and its indication were also recorded.

\section{Intervention and data analysis}

In the retrospective phase 1 study, microbiology data from all cases with GNB CRBSI were reviewed, but only cases that met the inclusion and exclusion criteria were selected for clinical analysis. The distribution of antibiotic duration was analyzed and a cut-off point was determined to divide patients into two groups; the longduration group and the short-duration group. Patients' baseline characteristics and clinical outcomes were compared between the two groups. For the categorical variables, the chi-squared test was used. For the continuous variables, the Shapiro-Wilk test was used to test for normality. The Mann-Whitney test and an unpaired t test were used for the comparison if the data were nonnormally distributed and normally distributed, respectively. Variables with significances of $p<0.05$ in the bivariate analysis were included in the multiple logistic regression analysis to identify factors associated with relapse or mortality, and to determine whether shortening the duration of antibiotic therapy was associated with poor outcomes.

For the prospective phase 2 study, patients were assigned to receive short-duration antibiotic therapy for 7 days. The choice of antibiotic was made by their physicians. The duration of therapy was counted from the first day that patients had their catheters removed and received appropriate antibiotic treatment until that treatment was interrupted. Total duration of antibiotics including treatment before catheter removal were no longer than 10 days. Catheter reinsertion could be performed only after the patients had received appropriate antibiotic treatment. Two specimens of hemoculture were taken at 7 days after discontinuation of antibiotic therapy, as a patient safety surveillance measure. Cases with positive surveillance hemoculture were treated by physicians according to standards of care.

Patients without risk factor for relapse found in the phase 1 study, who received antibiotic therapy of at least 14 days, were selected from the phase 1 study to form a long-duration group for phase 2 . The ratio between the long- and short-duration groups was 3:1. Patients were selected consecutively with best-matched characteristics, consisting of immunocompromised status, age, underlying cancer, ICU admission at onset of CRBSI, and Charlson comorbidity index. These characteristics were chosen because of their possible impact on the patients' immune response and clinical outcomes. Baseline characteristics and clinical outcomes were then compared between the two groups, using statistics, as in the phase 1 study. All statistical analyses were performed using $\mathrm{IBM}^{\bullet} \mathrm{SPSS}^{\bullet}$ Statistics version 18.

\section{Results}

A total of 174 cases with a confirmed diagnosis of GNB CRBSI were identified. Microbial etiology was monomicrobial in 161 cases and polymicrobial in 13 cases $(2$ cases of $1 \mathrm{GNB}$ and 1 Gram-positive bacteria, 10 cases of $2 \mathrm{GNB}$, and 1 case of $3 \mathrm{GNB}$ ). Various GNB pathogens were found, as shown in Table 1. Three most common pathogens associated with nosocomial infections were $P$. aeruginosa (23.2\%), Klebsiella pneumoniae (17.2\%), and Acinetobacter baumannii (15.2\%). For healthcare-associated infections, four common pathogens were $P$. aeruginosa (17.6\%), Burkholderia cepacia complex (17.6\%), K. pneumoniae (14.7\%), and Enterobacter cloacae (14.7\%).

Of all, 89 episodes of infection occurred while patients were receiving antibiotic therapy. The most common receiving antibiotics were carbapenems, piperacillin/tazobactam, and vancomycin. Breakthrough infections were likely caused by Acinetobacter spp., Pseudomonas spp., and Stenotrophomonas maltophilia. Organisms associated with breakthrough infections among patients receiving each antibiotic are shown in Table 2.

Of the 174 cases of GNB CRBSI, 8 patients did not meet the inclusion criteria (no appropriate antibiotics), whereas 9 patients were excluded according to the exclusion criteria. Another 14 patients were excluded because patients received antibiotics with a duration of less than 7 days, the minimum duration recommended by the IDSA guidelines. One patient was further excluded because the catheter had been removed after completion of antibiotic therapy. In addition, the information on two patients was incomplete because the patients were transferred to another hospital. This left a total of 140 patients for clinical analysis. Patients were prescribed antibiotics for 7 to 39 days. Distribution of the duration of antibiotic therapy is shown in Fig. 1. Fourteen days was chosen as a cut-off point to divide patients into two groups: the long-duration ( $\geq 14$ day) group and the shortduration $(<14$ day) group.

Patients' characteristics and outcomes in both groups are shown in Table 3. Indications for catheter placement were hemodialysis, nutrition support, 
Table 1 Gram-negative bacteria associated with catheter-related bloodstream infection according to origin of infection

\begin{tabular}{|c|c|c|c|c|}
\hline \multirow[t]{2}{*}{ Organisms } & \multirow{2}{*}{$\begin{array}{l}\text { Total (\%) } \\
(N=186)\end{array}$} & \multicolumn{3}{|l|}{ Origin of infection } \\
\hline & & Community-acquired $(\%)(N=1)$ & Healthcare-associated (\%) $(N=34)$ & Nosocomial $(\%)(N=151)$ \\
\hline Pseudomonas aeruginosa & $41(22.0)$ & - & $6(17.6)$ & $35(23.2)$ \\
\hline Klebsiella pneumoniae & $31(16.7)$ & - & $5(14.7)$ & $26(17.2)$ \\
\hline Stenotrophomonas maltophilia & $25(13.4)$ & - & $3(8.8)$ & $22(14.6)$ \\
\hline Acinetobacter baumannii & $24(12.9)$ & - & $1(2.9)$ & $23(15.2)$ \\
\hline Escherichia coli & $18(9.7)$ & - & $1(2.9)$ & $17(11.3)$ \\
\hline Burkholderia cepacia complex & $12(6.5)$ & - & $6(17.6)$ & $6(4.0)$ \\
\hline Enterobacter cloacae & $11(5.9)$ & - & $5(14.7)$ & $6(4.0)$ \\
\hline Serratia marcescens & $6(3.2)$ & - & - & $6(4.0)$ \\
\hline Enterobacter aerogenes & $4(2.2)$ & - & $2(5.9)$ & $2(1.3)$ \\
\hline Chryseobacterium indologenes & $2(1.1)$ & - & - & $2(1.3)$ \\
\hline Elizabethkingia meningoseptica & $2(1.1)$ & - & - & $2(1.3)$ \\
\hline Ralstonia (Pseudomonas) pickettii & $2(1.1)$ & - & $2(5.9)$ & - \\
\hline Acinetobacter baylyi & $1(0.5)$ & - & - & $1(0.7)$ \\
\hline Acinetobacter junii & $1(0.5)$ & $1(100.0)$ & - & - \\
\hline Acinetobacter nosocomialis & $1(0.5)$ & - & $1(2.9)$ & - \\
\hline Aeromonas hydrophila & $1(0.5)$ & - & $1(2.9)$ & - \\
\hline Citrobacter freundii & $1(0.5)$ & - & - & $1(0.7)$ \\
\hline Ochrobactrum anthropi & $1(0.5)$ & - & $1(2.9)$ & - \\
\hline Proteus mirabilis & $1(0.5)$ & - & - & $1(0.7)$ \\
\hline Pseudomonas chlororaphis & $1(0.5)$ & - & - & $1(0.7)$ \\
\hline
\end{tabular}

medications, hemodynamic monitoring, fluid transfusion, and blood transfusion. We were unable to identify exact indications in some cases, because these data were not routinely recorded in the medical charts. There were only 9 patients with relapse among 140 patients (6.4\%). The number of patients and mortality rate were 34 and $24.3 \%$, respectively. Comparing the long-duration group and the shortduration group, overall relapse rates were not different, but greater mortality was observed in the shortduration group. Eleven patients in the short-duration and 8 patients in the long-duration group died during treatment. Thirty-three patients received antibiotics within the 30 -day follow-up period (26 patients in the long-duration group and 7 patients in the short-duration group). No difference was found between the two groups in time to next antibiotic use. The patients' characteristics were compared according to relapse and death. Catheter retention was the only risk factor that was found to significantly increase the risk of relapse (odds ratio $=145.32 ; 95 \%$ confidence interval 12.66-1667.37, $P<0.001)$. No significant risk factor for mortality was found (Table 4).

In the prospective phase 2 study, there were 80 patients with GNB CRBSI. However, inclusion criteria were met for only 27 patients. Sixteen patients were excluded according to exclusion criteria (4 with catheter retention, which was the only risk factor for relapse found in the phase 1 study; 1 with ongoing neutropenia; 1 with abdominal abscess; 1 with osteomyelitis; 1 with septic arthritis; 4 with other indications for antibiotic continuation; and 1 due to patient's refusal to participate). One case was withdrawn because the patient was transferred to another hospital and 2 cases were withdrawn due to death before antibiotic discontinuation, leaving 11 patients recruited into the short-duration group. The patients in this group were mainly immunocompetent, with nosocomial infections. The catheter type and indication varied. During the follow-up period, no relapse was found. Antibiotics were restarted in 3 patients for conditions unrelated to the GNB CRBSI. Surveillance hemocultures were performed 7 days after antibiotic discontinuation except for 2 patients, from whom hemocultures were taken on day 8 due to outpatient hospital visits. The results were negative except in one patient, whose culture was positive for K. pneumoniae and Candida glabrata, with the diagnosis of intra-abdominal infection with septicemia.

Thirty-three matched patients with catheter removal from the phase 1 study who received antibiotics $\geq 14$ days were selected for the long-duration group. Comparisons of patients' characteristics and clinical outcomes 


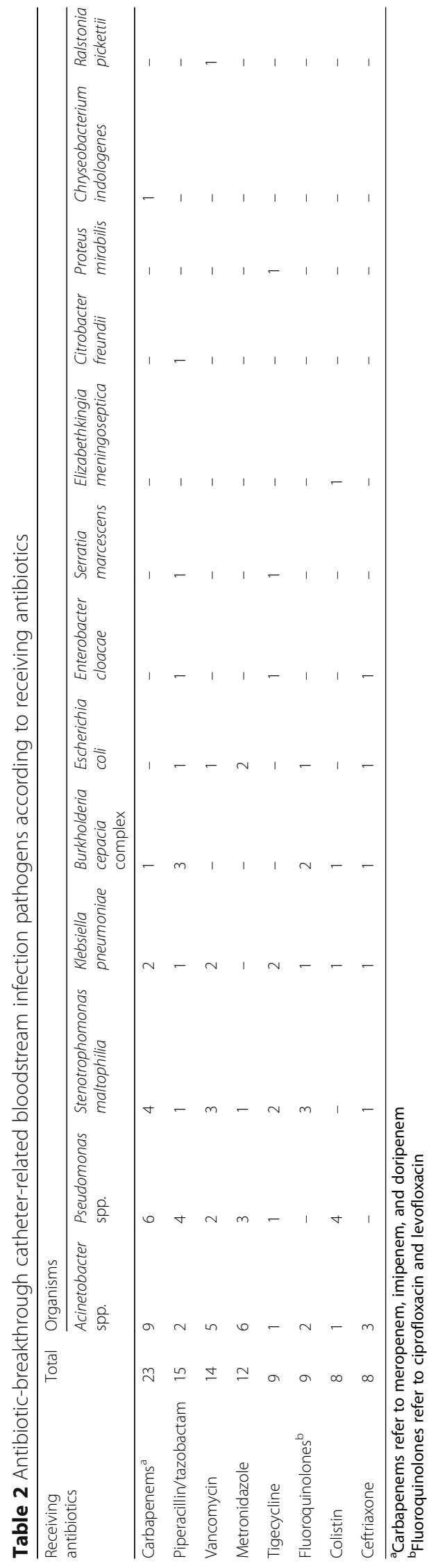




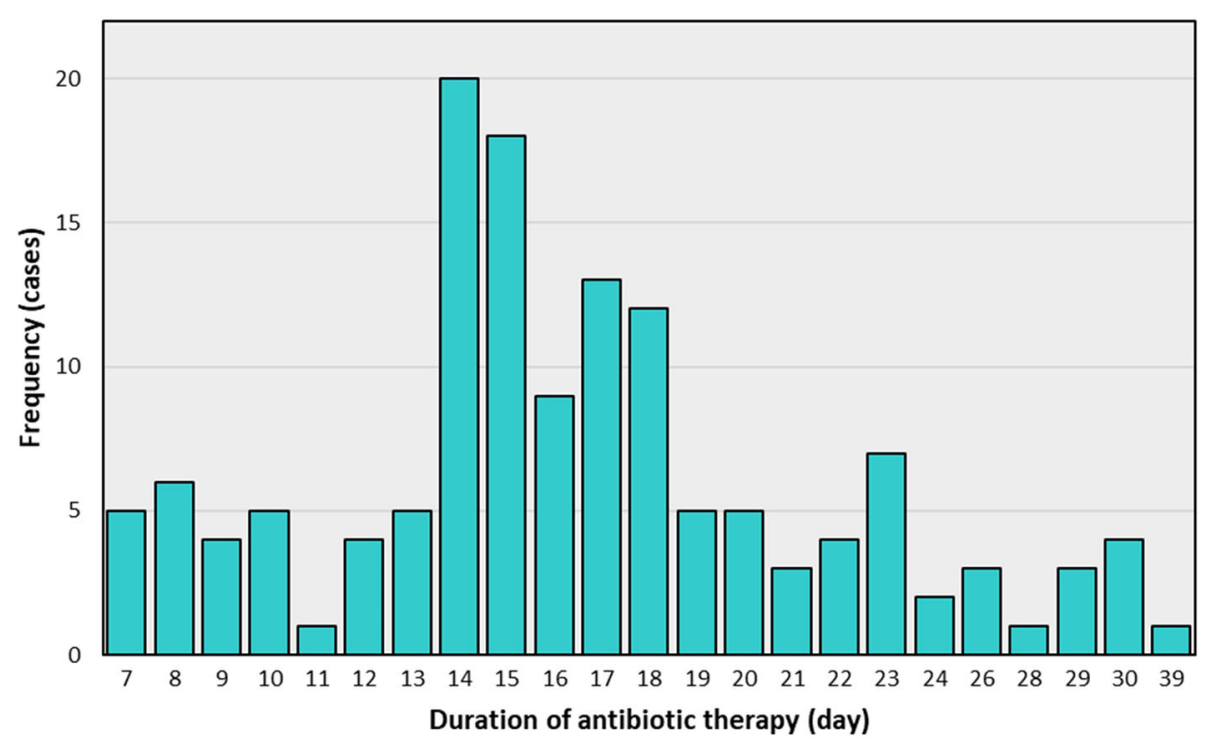

Fig. 1 Distribution of antibiotic therapy duration physicians used to treat Gram-negative bacteria catheter-related bloodstream infection

between the long- and short-duration groups are shown in Table 5. Outcomes were comparable between the two groups.

\section{Discussion}

During the 7-year duration of the phase 1 study, there were 174 cases of patients with GNB CRBSI. This low number of cases was due to the strict IDSA diagnostic criteria used, which required laboratory evidence to confirm that the catheter was the source of infection [8], which is different from many studies that use central lineassociated bloodstream infection (CLABSI) definition. CLABSI is defined as a bloodstream infection in a patient who had a central line within the 48-h period before the infection occurs. CLABSI may overestimate the true incidence of CRBSI and is used for surveillance purpose [11]. The most common pathogens found in our study were $P$. aeruginosa. These findings are similar to studies in Israel and Spain that reported $P$. aeruginosa as the CRBSI pathogen for approximately $28 \%$ of cases [5, 7]. Approximately half of cases in our study were breakthrough infections while on antibiotic therapy. Carbapenems were the most common antibiotics used at that time. The most common pathogens causing breakthrough infections were Acinetobacter spp., Pseudomonas spp., and S. maltophilia., all of which are major problems in terms of drug-resistant, nosocomial, GNB pathogens. To the best of our knowledge, this is the first report of microbial epidemiology in breakthrough GNB CRBSI.

From the 140 patients included in clinical analysis, most patients had been prescribed with long-duration therapy, given using a 14-day cut-off resulted in a small number of patients with short-duration therapy. Long- duration antibiotics were more likely prescribed in patients with underlying renal disease, healthcareassociated infections, or tunnel hemodialysis catheter. However, none of these factors were reported to be risk factors for relapse or death. This showed that physicians here still preferred to extend the duration of treatment even though the IDSA guidelines suggested a minimum duration of 7 days [8]. The possible explanation was short duration of antibiotic treatment was not a common practice in our setting. Moreover, as there is universal health-care coverage scheme in Thailand, there was no need for the patients to pay for the cost of longduration antibiotic treatment. Other guidelines from the Spanish Society of Infectious Diseases and Clinical Microbiology and the Spanish Society of Spanish Society of Intensive and Critical Care Medicine and Coronary Units have suggested that the duration of therapy should be individualized, and at least 7-day antibiotic treatment has been recommended [12].

Compared with reported relapse rates between 7.5 and $11.1 \%$, a low relapse rate of only $6.4 \%$ was found in our phase 1 study [13-15]. There was no difference in relapse rates between patients in the long- and short-duration groups. From the bivariate analysis, despite three factors that could affect the outcome (ICU admission at onset of CRBSI, type of catheter, and catheter management), only catheter retention was strongly associated with relapse. This is consistent with a previous study of children with uncomplicated GNB bacteremia in which the main sources of infection were CRBSI, with reported catheter retention and polymicrobial bacteremia as risk factors for relapse [16]. On the other hand, catheter removal had also been reported as an independent protective factor against 
Table 3 Characteristics and clinical outcomes of patients treated with long-duration and short-duration antibiotic in the phase 1 study

\begin{tabular}{|c|c|c|c|}
\hline Characteristics and outcomes & Long-duration group $(N=110)$ & Short-duration group $(N=30)$ & $p$-value \\
\hline \multicolumn{4}{|l|}{ Characteristics } \\
\hline Age (years) & $66(18-95)$ & $74(28-97)$ & 0.064 \\
\hline \multicolumn{4}{|l|}{ Sex } \\
\hline Male & $59(53.6 \%)$ & $19(63.3 \%)$ & 0.410 \\
\hline Female & $51(46.4 \%)$ & $11(36.7 \%)$ & 0.410 \\
\hline Charlson comorbidity index (score) & $6(0-14)$ & $6(0-14)$ & 0.383 \\
\hline \multicolumn{4}{|l|}{ Underlying diseases } \\
\hline HIV infection & $1(0.9 \%)$ & $0(0.0 \%)$ & 1.000 \\
\hline Cancer & $27(24.5 \%)$ & $12(40.0 \%)$ & 0.110 \\
\hline Liver disease & $7(6.4 \%)$ & $3(10.0 \%)$ & 0.446 \\
\hline Renal disease & $49(44.5 \%)$ & $5(16.7 \%)$ & $0.006^{\mathrm{a}}$ \\
\hline COPD & $4(3.6 \%)$ & $3(10.0 \%)$ & 0.169 \\
\hline Diabetes mellitus & $42(38.2 \%)$ & $7(23.3 \%)$ & 0.194 \\
\hline Hematological disease & $9(8.2 \%)$ & $3(10.0 \%)$ & 0.720 \\
\hline Cardiovascular disease & $23(20.9 \%)$ & $5(16.7 \%)$ & 0.798 \\
\hline Trauma & $3(2.7 \%)$ & $2(6.7 \%)$ & 0.291 \\
\hline Immunocompromised status & $22(20.0 \%)$ & $10(33.3 \%)$ & 0.143 \\
\hline \multicolumn{4}{|l|}{ Microbial etiology } \\
\hline Monomicrobial & $106(96.4 \%)$ & $27(90.0 \%)$ & 0.169 \\
\hline Polymicrobial & $4(3.6 \%)$ & $3(10.0 \%)$ & 0.169 \\
\hline \multicolumn{4}{|l|}{ Origin of infection } \\
\hline Healthcare-associated & $31(28.2 \%)$ & $0(0.0 \%)$ & $<0.001^{\mathrm{a}}$ \\
\hline Nosocomial & $79(71.8 \%)$ & $30(100.0 \%)$ & $<0.001^{\mathrm{a}}$ \\
\hline ICU admission at onset of infection & $49(44.5 \%)$ & $22(73.3 \%)$ & $0.007^{\mathrm{a}}$ \\
\hline Surgery at present admission & $57(51.8 \%)$ & $19(63.3 \%)$ & 0.305 \\
\hline \multicolumn{4}{|l|}{ Type of catheter } \\
\hline Tunneled hemodialysis catheter & $31(28.2 \%)$ & $1(3.3 \%)$ & $0.003^{\mathrm{a}}$ \\
\hline Short-term central venous catheter or arterial catheter & $58(52.7 \%)$ & $23(76.7 \%)$ & $0.022^{\mathrm{a}}$ \\
\hline Long-term central venous catheter or port & $21(19.1 \%)$ & $6(20.0 \%)$ & 1.000 \\
\hline \multicolumn{4}{|l|}{ Catheter management } \\
\hline Catheter retention & $9(8.2 \%)$ & $2(6.7 \%)$ & 1.000 \\
\hline Catheter removal & $101(91.8 \%)$ & $28(93.3 \%)$ & 1.000 \\
\hline Total duration of therapy (day) & $17(14-39)$ & $10(7-13)$ & $<0.001^{\mathrm{a}}$ \\
\hline Duration of therapy after catheter removal (day) & $15(1-28)$ & $8(3-13)$ & $<0.001^{\mathrm{a}}$ \\
\hline \multicolumn{4}{|l|}{ Outcome } \\
\hline Relapse & $7(6.4 \%)$ & $2(6.7 \%)$ & 1.000 \\
\hline Death $^{b}$ & $19(17.3 \%)$ & $15(50.0 \%)$ & $0.001^{a}$ \\
\hline Time to next antibiotic use (hour) & $233.3(54.0-960.0)$ & $392.5(102.0-504.0)$ & 0.268 \\
\hline \multicolumn{4}{|l|}{ Indication of next antibiotic used } \\
\hline New infectious episode & $13(11.8 \%)$ & $2(6.7 \%)$ & 0.413 \\
\hline Non-infectious episode & $1(0.9 \%)$ & $1(3.3 \%)$ & 0.384 \\
\hline Relapse & $6(5.5 \%)$ & $2(6.7 \%)$ & 1.000 \\
\hline Undetermined episode & $6(5.5 \%)$ & $2(6.7 \%)$ & 1.000 \\
\hline
\end{tabular}

${ }^{a} p$-value $<0.05$

${ }^{b}$ Eleven patients in the short-duration and 8 patients in the long-duration group died during treatment

Abbreviations: HIV human immunodeficiency virus, COPD chronic obstructive pulmonary disease, ICU intensive care unit

Data were presented as frequency (percent) except for age, Charlson comorbidity index, total duration of therapy, duration of therapy after catheter removal, and time to next antibiotic use, which were presented as median (minimum-maximum) 
Table 4 Risk factors for relapse and death in patients with Gram-negative bacteria catheter-related bloodstream infection

\begin{tabular}{|c|c|c|c|c|c|c|c|c|}
\hline \multirow{2}{*}{ Characteristics } & \multicolumn{4}{|c|}{ Relapse } & \multicolumn{4}{|l|}{ Death } \\
\hline & $\begin{array}{l}\text { Yes } \\
(N=9)\end{array}$ & $\begin{array}{l}\text { No } \\
(N=131)\end{array}$ & $p$-value & $\begin{array}{l}\text { Multivariate } \\
\text { analysis } \\
\text { OR }(95 \% \mathrm{Cl}) \text {, } \\
\text { p-value }\end{array}$ & $\begin{array}{l}\text { Yes } \\
(N=34)\end{array}$ & $\begin{array}{l}\text { No } \\
(N=106)\end{array}$ & $p$-value & $\begin{array}{l}\text { Multivariate } \\
\text { analysis } \\
\text { OR }(95 \% \mathrm{Cl}) \text {, } \\
\text { p-value }\end{array}$ \\
\hline Age & 69 & 66 & 0.171 & & 63 & 67 & 0.800 & \\
\hline \multicolumn{9}{|l|}{ Sex } \\
\hline Male & 5 & 73 & 1.000 & & 22 & 56 & 0.241 & \\
\hline Female & 4 & 58 & & & 12 & 50 & & \\
\hline Charlson comorbidity index & 7 & 5 & 0.075 & & 5 & 6 & 0.694 & \\
\hline \multicolumn{9}{|l|}{ Underlying diseases } \\
\hline HIV infection & 0 & 1 & 1.000 & & 0 & 1 & 1.000 & \\
\hline Cancer & 4 & 35 & 0.264 & & 13 & 26 & 0.130 & \\
\hline Liver disease & 0 & 10 & 1.000 & & 4 & 6 & 0.256 & \\
\hline Renal disease & 5 & 49 & 0.307 & & 7 & 47 & $0.015^{\mathrm{a}}$ & $\begin{array}{l}0.630(0.216- \\
1.895) 0.420\end{array}$ \\
\hline COPD & 1 & 6 & 0.379 & & 2 & 5 & 0.677 & \\
\hline Diabetes mellitus & 6 & 43 & 0.066 & & 7 & 42 & 0.062 & \\
\hline Hematological disease & 1 & 11 & 0.565 & & 6 & 6 & 0.071 & \\
\hline Cardiovascular disease & 3 & 25 & 0.383 & & 5 & 23 & 0.465 & \\
\hline Trauma & 0 & 5 & 1.000 & & 3 & 2 & 0.092 & \\
\hline Immunocompromised status & 2 & 30 & 1.000 & & 11 & 21 & 0.160 & \\
\hline \multicolumn{9}{|l|}{ Microbial etiology } \\
\hline Monomicrobial & 9 & 124 & 1.000 & & 32 & 101 & 0.677 & \\
\hline Polymicrobial & 0 & 7 & & & 2 & 5 & & \\
\hline \multicolumn{9}{|l|}{ Origin of infection } \\
\hline Healthcare-associated & 3 & 28 & 0.415 & & 0 & 31 & $<0.001^{\mathrm{a}}$ & $\begin{array}{l}266,606,914.2 \\
(<0.001 \text {-infinity) } \\
0.998\end{array}$ \\
\hline Nosocomial & 6 & 103 & & & 34 & 75 & & \\
\hline ICU admission at onset of infection & 1 & 70 & $0.017^{\mathrm{a}}$ & $\begin{array}{l}0.173(0.005- \\
6.394), 0.341\end{array}$ & 26 & 45 & $0.001^{\mathrm{a}}$ & $\begin{array}{l}1.803(0.590- \\
5.512) 0.301\end{array}$ \\
\hline Surgery at present admission & 2 & 74 & 0.080 & & 24 & 52 & $0.031^{\mathrm{a}}$ & $\begin{array}{l}0.763(0.279- \\
2.086) 0.598\end{array}$ \\
\hline \multicolumn{9}{|l|}{ Type of catheter } \\
\hline Tunneled hemodialysis catheter & 5 & 27 & $0.029^{a}$ & $\begin{array}{l}10.023(0.559- \\
179.714), 0.118\end{array}$ & 1 & 31 & $0.001^{\mathrm{a}}$ & $\begin{array}{l}1.013(0.074- \\
13.929) 0.992\end{array}$ \\
\hline $\begin{array}{l}\text { Short-term central venous } \\
\text { catheter or arterial catheter }\end{array}$ & 2 & 79 & $0.036^{\mathrm{a}}$ & $\begin{array}{l}2.320(0.072- \\
74.855), 0.635\end{array}$ & 29 & 52 & $<0.001^{\mathrm{a}}$ & $\begin{array}{l}2.214(0.599- \\
8.187) 0.233\end{array}$ \\
\hline $\begin{array}{l}\text { Long-term central venous } \\
\text { catheter or port }\end{array}$ & 2 & 25 & 0.684 & & 4 & 23 & 0.317 & \\
\hline \multicolumn{9}{|l|}{ Catheter management } \\
\hline Catheter retention & 7 & 4 & $<0.001^{\mathrm{a}}$ & $\begin{array}{l}145.315(12.665- \\
1667.369),<0.001^{\text {a }}\end{array}$ & 4 & 7 & 0.462 & \\
\hline Catheter removal & 2 & 127 & & & 30 & 99 & & \\
\hline Total duration of therapy & 14 & 16 & 0.269 & $\begin{array}{l}0.855(0.623- \\
1.172) 0.330\end{array}$ & 15 & 16 & 0.264 & $\begin{array}{l}0.990(0.923- \\
1.062) 0.781\end{array}$ \\
\hline Duration of therapy after catheter removal & 13 & 14 & 0.946 & & 11 & 14 & $0.039^{\mathrm{a}}$ & \\
\hline
\end{tabular}

ap-value $<0.05$

Abbreviations: HIV human immunodeficiency virus, COPD chronic obstructive pulmonary disease, ICU intensive care unit

Data were presented as count except age, Charlson comorbidity index, total duration of therapy, duration of therapy after catheter removal, which were presented as median 
Table 5 Comparison of patients with catheter removal receiving long- and short-duration antibiotic in the phase 2 study

\begin{tabular}{|c|c|c|c|}
\hline Characteristics and outcomes & Long-duration group $(N=33)$ & Short-duration group $(N=11)$ & $p$-value \\
\hline \multicolumn{4}{|l|}{ Characteristics } \\
\hline Age (year) & $67(18-81)$ & $68(24-81)$ & 0.979 \\
\hline \multicolumn{4}{|l|}{ Gender } \\
\hline Male & $16(48.5 \%)$ & $5(45.5 \%)$ & 1.000 \\
\hline Female & $17(51.5 \%)$ & $6(54.5 \%)$ & 1.000 \\
\hline Charlson comorbidity index (score) & $5(0-12)$ & $4(0-10)$ & 0.936 \\
\hline \multicolumn{4}{|l|}{ Underlying diseases } \\
\hline HIV infection & $0(0.0 \%)$ & $0(0.0 \%)$ & - \\
\hline Cancer & $7(21.2 \%)$ & $3(27.3 \%)$ & 0.692 \\
\hline Liver disease & $1(3.0 \%)$ & $1(9.1 \%)$ & 0.442 \\
\hline Renal disease & $16(48.5 \%)$ & $4(36.4 \%)$ & 0.728 \\
\hline COPD & $1(3.0 \%)$ & $0(0.0 \%)$ & 1.000 \\
\hline Diabetes mellitus & $13(39.4 \%)$ & $5(45.5 \%)$ & 0.738 \\
\hline Hematological disease & $2(6.1 \%)$ & $1(9.1 \%)$ & 1.000 \\
\hline Cardiovascular disease & $8(24.2 \%)$ & $7(63.6 \%)$ & $0.028^{\mathrm{a}}$ \\
\hline Trauma & $1(3.0 \%)$ & $0(0.0 \%)$ & 1.000 \\
\hline Immunocompromised status & $6(18.2 \%)$ & $2(18.2 \%)$ & 1.000 \\
\hline \multicolumn{4}{|l|}{ Microbial etiology } \\
\hline Monomicrobial & 31 (93.9\%) & 10 (90.9\%) & 1.000 \\
\hline Polymicrobial & $2(6.1 \%)$ & $1(9.1 \%)$ & 1.000 \\
\hline \multicolumn{4}{|l|}{ Origin of infection } \\
\hline Healthcare-associated & $9(27.3 \%)$ & $1(9.1 \%)$ & 0.408 \\
\hline Nosocomial & $24(72.7 \%)$ & $10(90.9 \%)$ & 0.408 \\
\hline ICU admission at onset of infection & $13(39.4 \%)$ & $4(36.4 \%)$ & 1.000 \\
\hline Surgery at present admission & $18(54.5 \%)$ & $6(54.5 \%)$ & 1.000 \\
\hline \multicolumn{4}{|l|}{ Type of catheter } \\
\hline Tunneled hemodialysis catheter & $10(30.3 \%)$ & $2(18.2 \%)$ & 0.698 \\
\hline Short-term central venous catheter or arterial catheter & $19(57.6 \%)$ & $4(36.4 \%)$ & 0.303 \\
\hline Long-term central venous catheter or port & $4(12.1 \%)$ & $5(45.5 \%)$ & $0.030^{\mathrm{a}}$ \\
\hline Total duration of therapy (day) & $17(14-30)$ & $7(7-10)$ & $<0.001^{\mathrm{a}}$ \\
\hline Duration of therapy after catheter removal (day) & $14(1-23)$ & $7(7-7)$ & $<0.001^{\mathrm{a}}$ \\
\hline \multicolumn{4}{|l|}{ Outcome } \\
\hline Relapse & $1(3.0 \%)$ & $0(0.0 \%)$ & 1.000 \\
\hline Death & $4(12.1 \%)$ & $1(9.1 \%)$ & 1.000 \\
\hline Time to next antibiotic use (hour) & $357.25(54.0-444.0)$ & $224.0(176.0-312.75)$ & 0.400 \\
\hline \multicolumn{4}{|l|}{ Indication of next antibiotic used } \\
\hline New infectious episode & $3(9.1 \%)$ & $2(18.2 \%)$ & 1.000 \\
\hline Non-infectious episode & $0(0.0 \%)$ & $0(0.0 \%)$ & - \\
\hline Relapse & $1(3.0 \%)$ & $0(0.0 \%)$ & 1.000 \\
\hline Undetermined episode & $0(0.0 \%)$ & $1(9.1 \%)$ & 0.429 \\
\hline
\end{tabular}

${ }^{a} p$-value $<0.05$

Abbreviations: HIV human immunodeficiency virus, COPD chronic obstructive pulmonary disease, ICU intensive care unit Data were presented as frequency (percent) except for age, Charlson comorbidity index, total duration of therapy, duration of therapy after catheter removal and time to next antibiotic use, which were presented as median (minimum-maximum) 
relapse in a study of GNB CRBSI [15]. Relapse in patients without catheter removal could be related to biofilm formation on the external surface or inner lumen of the catheter [17]. In addition to Gram-positive bacteria, GNB were able to produce biofilm, as shown in an in vitro system in which human blood components had promoted adhesion and biofilm formation [18]. Apart from catheter removal, prolonged-duration of antibiotics does not show evidence to support reduced relapse risk $[14,16]$.

For the fatal outcome, the short-duration group in the phase 1 study had significantly more deaths than the long-duration group. This could be explained by the fact that patients who died during antibiotic treatment were not excluded. From the 30 patients in the short-duration group, 11 patients (36.7\%) were recruited into this group because antibiotics were discontinued due to their deaths, whereas only 8 patients $(7.3 \%)$ died before antibiotic discontinuation among the 110 patients in the long-duration group. In addition, we could not find that antibiotic duration was associated with death at all. Characteristics of patients in the short-duration group were more likely to be patients with nosocomial infection, ICU admission at onset of infection, and shortterm central venous catheter. This might reflect the patients' severity of illness that could have resulted in more deaths. Despite the many possible risk factors for death that were found in the bivariate analysis (underlying renal disease, origin of infection, ICU admission at onset of CRBSI, surgery at present admission, duration of antibiotic after catheter removal, and type of catheter), no significant risk factor was found in the multivariate analysis. Compared with previously reported risk factors for death, which were catheter retention [19], surgery in the present admission, infection caused by $P$. aeruginosa, complicated bacteremia (recurrence, septic arthritis, wound infection) [13], male patients, and catheterizations with triple lumen type catheters [20], our study found that surgery at present admission and type of catheter (short-term central venous catheter or arterial catheter and tunneled hemodialysis catheter) were also possible risks but were not found to be significant in the multivariate analysis. Catheter retention and male patients were not found to be significant risk factors in this study. Infection caused by $P$. aeruginosa was not tested due to various other pathogens found. Complicated bacteremia was excluded from the exclusion criteria.

In the 1-year-prospective part of the study (phase 2), there were only 11 patients recruited to receive shortduration antibiotic treatment. Reasons for the low number of participants were due to the strict diagnostic criteria used, and because only patients with catheter removal were selected. After matching with patients receiving long-duration therapy, patients in the shortduration group had significantly more underlying cardiovascular diseases and types of catheterization: long-term central venous catheter or port. However, these characteristics showed no association with focused clinical outcome as no significant risk factors for relapse or death were found from a bivariate analysis (data not shown). Comparing these matched patients, outcomes between the 2 groups were not different. Despite the short-duration of therapy, no relapse was found. To the best of our knowledge, this study is the first prospective study to evaluate the outcome of short-duration treatment of uncomplicated GNB CRBSI in patients with catheter removal. Results show that prolonged-duration of antibiotics might not have additional benefits in the prevention of relapse, because relapse risk should already be low after the catheters have been removed. This supports the concept of shortening the duration of antibiotic therapy, evidence for which is increasing for many infectious diseases [21-23]. A study in children with uncomplicated GNB bacteremia, in which CRBSIs were the main sources of infection, found that prolonged antibiotic treatment did not reduce relapse risk [16]. Another study of patients with GNB CLABSI in the surgical trauma ICU found similar duration of therapy in patients with and without recurrence [14]. Nevertheless, these two studies included patients without catheter removal. Other studies of patients with GNB bacteremia from various source of infection, including CRBSI, found no difference in many outcomes, which were relapse, death, Clostridium difficile infection, suppurative or distant complications, readmission, or extended hospitalization between patients treated with long- and short-duration therapy [24-26].

This study collected data on many cases of GNB CRBSI over a long period of time. Our strict diagnostic criteria could be a strength of our study, given the criteria might specify catheters as the true primary source of bloodstream infection. Various pathogens, including multidrug-resistant nonfermented GNB, have been reported. Unlike most of the other studies that have been conducted in patients with uncomplicated GNB bacteremia from Enterobacteriaceae as the main pathogens, results from this study can be specifically applied for patients with CRBSI. One limitation in this study was that patients who died before completing the course of treatment were included, thus, the duration of therapy among these patients did not reflect the true duration. However, all patients had already received antibiotics for at least 7 days, which was the suggested minimum duration, and short duration of antibiotics was not found to increase risk of death. Only a few patients could be enrolled in the prospective study due to the limitation of a 1-year study period and the hospital's infection control policy of the CLABSI bundle to reduce risk of CRBSI 
leading to lower prevalence of this condition. However, results from this study could lead to larger trials on the efficacy of shortening the duration of antibiotic therapy for uncomplicated GNB CRBSI.

\section{Conclusions}

We confirm that catheter removal is crucial for the management of GNB CRBSI, because that is the most important action that can be performed to prevent relapse. The empiric antibiotic should be broad-spectrum, with coverage of $P$. aeruginosa. In addition, short-duration treatment is possible for patients with uncomplicated GNB CRBSI who have had their catheters removed.

\section{Abbreviations}

CRBSI: Catheter-related bloodstream infection; GNB: Gram-negative bacteria; IDSA: The Infectious Diseases Society of America; HIV: Human immunodeficiency virus; COPD: Chronic obstructive pulmonary disease; ICU: Intensive care unit; CLABSI: Central line-associated bloodstream infection

\section{Acknowledgments}

We give special thanks to the microbiology laboratory staff and to infection control nurses for their help in case identification and to all infectious disease staff and fellows on patients' management.

\section{Authors' contributions}

BS designed the study, recruited patients, collected patients' data, conducted data analysis and drafted initial manuscript. PS helped identify cases from microbiology laboratory. KM and SK assisted protocol submission to ethic committee and helped with patients' intervention. PM and BC helped with study design, study conceptualization and data analysis. All authors read manuscript and final manuscript was approved by BC.

\section{Funding}

This study was not funded.

\section{Availability of data and materials}

The datasets used and/or analyzed during the current study are available from the corresponding author.

\section{Ethics approval and consent to participate}

This study was approved by Committee on Human Rights Related to Research Involving Human Subjects, Faculty of Medicine Ramathibodi Hospital, Mahidol University (MURA2016/555 \& MURA2016/648). Signed informed consents were not required for patients in the phase 1 study due to retrospective study design, but were required for all patients prospectively recruited to receive short-duration antibiotic therapy in the phase 2 study.

\section{Consent for publication}

Not applicable.

\section{Competing interests}

The authors declare that they have no competing interests.

\section{Author details}

${ }^{1}$ Department of Pharmacy, Faculty of Medicine Ramathibodi Hospital, Mahidol University, Bangkok, Thailand. 'Department of Pharmacy, Faculty of Pharmacy, Mahidol University, Bangkok, Thailand. ${ }^{3}$ Department of Medicine, Faculty of Medicine Ramathibodi Hospital, Mahidol University, Bangkok, Thailand. ${ }^{4}$ Department of Pathology, Faculty of Medicine Ramathibodi Hospital, Mahidol University, Bangkok, Thailand.
Received: 17 December 2019 Accepted: 30 July 2020

Published online: 17 August 2020

\section{References}

1. Crump JA, Collignon PJ. Intravascular catheter-associated infections. Eur J Clin Microbiol Infect Dis. 2000;19(1):1-8.

2. Mermel LA, Farr BM, Sherertz RJ, Raad II, O'Grady N, Harris JS, et al. Guidelines for the management of intravascular catheter-related infections. Clin Infect Dis. 2001:32(9):1249-72.

3. Safdar N, Mermel LA, Maki DG. The epidemiology of catheter-related infection in the critically ill. In: O'Grady N, Pittet D, editors. Catheter-related infections in the critically ill. New York: Kluwer; 2004. p. 1-23.

4. Chee L, Brown M, Sasadeusz J, MacGregor L, Grigg AP. Gram-negative organisms predominate in Hickman line-related infections in nonneutropenic patients with hematological malignancies. J Inf Secur. 2008; 56(4):227-33.

5. Marcos M, Soriano A, Inurrieta A, Martinez JA, Romero A, Cobos N, et al. Changing epidemiology of central venous catheter-related bloodstream infections: increasing prevalence of gram-negative pathogens. J Antimicrob Chemother. 2011;66(9):2119-25.

6. Rodriguez-Creixems M, Munoz P, Martin-Rabadan P, Cercenado E, Guembe M, Bouza E. Evolution and aetiological shift of catheter-related bloodstream infection in a whole institution: the microbiology department may act as a watchtower. Clin Microbiol Infect. 2013;19(9):845-51.

7. Braun E, Hussein K, Geffen Y, Rabino G, Bar-Lavie Y, Paul M. Predominance of gram-negative bacilli among patients with catheter-related bloodstream infections. Clin Microbiol Infect. 2014;20(10):O627-9.

8. Mermel LA, Allon M, Bouza E, Craven DE, Flynn P, O'Grady NP, et al. Clinical practice guidelines for the diagnosis and management of intravascular catheter-related infection: 2009 update by the Infectious Diseases Society of America. Clin Infect Dis. 2009:49(1):1-45.

9. Garner JS, Jarvis WR, Emori TG, Horan TC, Hughes JM. CDC definitions for nosocomial infections, 1988. Am J Infect Control. 1988;16(3):128-40.

10. Friedman ND, Kaye KS, Stout JE, McGarry SA, Trivette SL, Briggs JP, et al. Health care--associated bloodstream infections in adults: a reason to change the accepted definition of community-acquired infections. Ann Intern Med. 2002;137(10):791-7.

11. O'Grady NP, Alexander M, Burns LA, Dellinger EP, Garland J, Heard SO, et al. Guidelines for the prevention of intravascular catheter-related infections. Clin Infect Dis. 2011;52(9):e162-93.

12. Chaves F, Garnacho-Montero J, Del Pozo JL, Bouza E, Capdevila JA, de Cueto $\mathrm{M}$, et al. Diagnosis and treatment of catheter-related bloodstream infection: clinical guidelines of the Spanish Society of Infectious Diseases and Clinical Microbiology and (SEIMC) and the Spanish Society of Spanish Society of intensive and critical care medicine and coronary units (SEMI CYUC). Med Int. 2018;42(1):5-36.

13. Bouza E, Eworo A, Fernandez Cruz A, Reigadas E, Rodriguez-Creixems M, Munoz P. Catheter-related bloodstream infections caused by gram-negative bacteria. J Hosp Infect. 2013;85(4):316-20.

14. Duane TM, Kikhia RM, Wolfe LG, Ober J, Tessier JM. Understanding gramnegative central line-associated blood stream infection in a surgical trauma ICU. Am Surg. 2015;81(8):816-9.

15. Hanna H, Afif C, Alakech B, Boktour M, Tarrand J, Hachem R, et al. Central venous catheter-related bacteremia due to gram-negative bacilli: significance of catheter removal in preventing relapse. Infect Control Hosp Epidemiol. 2004;25(8):646-9.

16. Park SH, Milstone AM, Diener-West M, Nussenblatt V, Cosgrove SE, Tamma PD. Short versus prolonged courses of antibiotic therapy for children with uncomplicated gram-negative bacteraemia. J Antimicrob Chemother. 2014; 69(3):779-85.

17. Donlan RM. Biofilms and device-associated infections. Emerg Infect Dis. 2001;7(2):277-81.

18. Murga R, Miller JM, Donlan RM. Biofilm formation by gram-negative bacteria on central venous catheter connectors: effect of conditioning films in a laboratory model. J Clin Microbiol. 2001;39(6):2294-7.

19. Deshpande P, Jain A, Shah PS. Outcomes associated with early removal versus retention of peripherally inserted central catheters after diagnosis of catheter-associated infections in neonates. J Matern Fetal Neonatal Med. 2016;29(24):4082-7.

20. Cheewinmethasiri J, Chittawatanarat K, Chandacham K, Jirapongchareonlap T, Chotirosniramit N. Microbiology, risk factors and mortality of patients with 
intravenous catheter related blood stream infections in the surgical intensive care unit: a five-year, concurrent, case-controlled study. J Med Assoc Thail. 2014;97(Suppl 1):S93-101.

21. Spellberg B. The new antibiotic mantra-"shorter is better". JAMA Intern Med. 2016;176(9):1254-5.

22. Wald-Dickler N, Spellberg B. Short course antibiotic therapy-replacing Constantine units with "shorter is better". Clin Infect Dis. 2019;69(9):1476-9.

23. Barlam TF, Cosgrove SE, Abbo LM, MacDougall C, Schuetz AN, Septimus EJ, et al. Implementing an antibiotic stewardship program: guidelines by the Infectious Diseases Society of America and the Society for Healthcare Epidemiology of America. Clin Infect Dis. 2016;62(10):e51-77.

24. Chotiprasitsakul D, Han JH, Cosgrove SE, Harris AD, Lautenbach E, Conley AT, et al. Comparing the outcomes of adults with Enterobacteriaceae bacteremia receiving short-course versus prolonged-course antibiotic therapy in a multicenter, Propensity Score-Matched Cohort. Clin Infect Dis. 2018;66(2):172-7.

25. Yahav D, Franceschini E, Koppel F, et al. Seven Versus 14 Days of Antibiotic Therapy for Uncomplicated Gram-negative Bacteremia: A Noninferiority Randomized Controlled Trial. Clin Infect Dis. 2019;69(7):1091-8.

26. Sousa A, Perez-Rodriguez MT, Suarez M, Val N, Martinez-Lamas L, Nodar A, et al. Short- versus long-course therapy in gram-negative bacilli bloodstream infections. Eur J Clin Microbiol Infect Dis. 2019:38(5):851-7.

\section{Publisher's Note}

Springer Nature remains neutral with regard to jurisdictional claims in published maps and institutional affiliations.

Ready to submit your research? Choose BMC and benefit from:

- fast, convenient online submission

- thorough peer review by experienced researchers in your field

- rapid publication on acceptance

- support for research data, including large and complex data types

- gold Open Access which fosters wider collaboration and increased citations

- maximum visibility for your research: over $100 \mathrm{M}$ website views per year

At BMC, research is always in progress.

Learn more biomedcentral.com/submissions 